\title{
Purification and Kinetic Properties of Phenoloxidase from Pupae of the Housefly
}

\author{
Tatsuru Hara, Takuji Tsukamoto, ${ }^{\dagger}$ Kazunari Maruta \\ and Masaru Funatsu* \\ Laboratory of Biological Chemistry, Faculty of Agriculture, \\ Saga University, Saga 840, Japan \\ * Department of Applied Microbial Technology. \\ The Kumamoto Institute of Technology, \\ Kumamoto 860, Japan
}

Received December 19, 1988

\begin{abstract}
Phenoloxidase was purified from pupae of the housefty, Musca domestica $\mathrm{L}$. The purification procedures included ammonium sulfate precipitation, affinity chromatography and Sephadex G-200 gel filtration. The final preparations appear to be homogeneous based on results obtained from polyacrylamide gel electrophoresis. The molecular weight of phenoloxidase was estimated to be 330,000 , as determined by gel filtration. The kinetic properties of phenoloxidase were studied using six catecholamines as substrates. The preferred order of substrates for phenoloxidase was found to be $N$ - $\beta$ alanyldopamine $>$ dopamine $>N$-acetyldopamine $>$ norepinephrine $>$ epinephrine $>$ DOPA.
\end{abstract}

The drastic fluctuation in phenoloxidase (EC 1.14.18.1 in part) activity during metamorphosis of the housefly, Musca domestica L., has been well documented. ${ }^{1,2)}$ The most prominent change in housefly phenoloxidase activity occurred at the stage of pupation. Specifically, almost the highest phenoloxidase activity observed in homogenates of the final instar larvae disappeared suddenly in the homogenates of prepupae. ${ }^{1)}$ However, the disappearance of housefly phenoloxidase activity in prepupae does not imply vanishing of the enzyme, since a homogenate of the prepupae exhibited phenoloxidase activity upon the addition of an anionic detergent such as sodium dodecyl sulfate or an extract from aged pupae. ${ }^{2)}$ These observations suggest that phenoloxidase exists in an inactive form, latent phenoloxidase, in the prepupae, and that there exists an endogenous activator of latent phenoloxidase in aged pupae.

Housefly larval phenoloxidase has been purified and studied on the basis of its physico- chemical characteristics. ${ }^{3,4)}$ However, there have only been a few studies focusing on pupal phenoloxidase, which is believed to be involved in the sclerotization and melanization of housefly pupal cuticle. This report describes the purification of hemolymphatic phenoloxidase from pupae of the housefly and kinetic properties of purified phenoloxidase.

\section{Materials and Methods}

Materials. Larvae of the housefly, Musca domestica L., were reared on a moist mixture of wheat bran and yeast powder at room temperature. Puparium formation usually occurred six or seven days after hatching. The aged pupae, three days after puparium formation, were used in this study.

$( \pm) 3,4$-Dihydroxyphenylalanine $[( \pm) D O P A]$, dopamine, ( \pm )epinephrine, $( \pm)$ norepinephrine, and $N$ acetyldopamine were obtained from Sigma Chemical Co., St. Louis, Mo. $N$ - $\beta$-Alanyldopamine was synthesized by the method of Kramer et al. ${ }^{5)}$ The experimental values for the elemental analysis of the synthesized $N$ - $\beta$-alanyldopamine agreed well with the theoretical values. Other chemicals were of reagent grade.

$\dagger$ To whom correspondence should be addressed. 
Phenoloxidase assay. Phenoloxidase activity was determined essentially according to the method of Horowitz and Shen. ${ }^{6}$ During the purification procedure, the activity was determined using a molar extinction coefficient of 3715 for dopachrome. ${ }^{7)}$ A typical incubation medium $(3.0 \mathrm{ml})$ contained $50 \mathrm{~mm}$ phosphate buffer ( $\mathrm{pH} 6.0)$, purified phenoloxidase $(0.28 \mu \mathrm{g}$ for $N$ - $\beta$-alanyldopamine and $0.56 \mu \mathrm{g}$ for other substrates) and various concentrations of substrates. The incubation medium was preincubated for $10 \mathrm{~min}$ at $25^{\circ} \mathrm{C}$ prior to addition of substrates. The incubation was initiated by adding substrates to the incubation medium in a quartz cell in a JASCO UVIDEC 340 spectrophotometer. The incubation medium was stirred continuously at $25^{\circ} \mathrm{C}$. The process of oxidation of the substrate was measured by monitoring the changes in absorbance at $470 \mathrm{~nm}$ except for $N$ - $\beta$-alanyldopamine and $N$-acetyldopamine, the oxidations of which were monitored at $390 \mathrm{~nm}$.

Polyacrylamide gel disc electrophoresis. Analytical polyacrylamide gel electrophoresis was performed according to the method described by Davis. ${ }^{81}$ The gels were stained with Coomassie blue.

Protein assay. Protein was determined by the method of Lowry et al ${ }^{9)}$ with bovine serum albumin as the standard protein.

\section{Results}

\section{Preparation of crude extract}

Pupae of the housefly were homogenized with 4-fold ice-cold $10 \mathrm{~mm}$ phosphate buffer ( $\mathrm{pH} 7.0$ ) containing $50 \mathrm{~mm}$ sodium ascorbate. The homogenates were centrifuged at $6,000 \times g$ for $20 \mathrm{~min}$ at $4^{\circ} \mathrm{C}$ and the supernatant under the fat layer was collected as the crude extract.

\section{Preparation of crude phenoloxidase}

Crude extract was brought to $60 \%$ saturation with solid ammonium sulfate. The resulting precipitate was collected by centrifugation and dialyzed against $50 \mathrm{~mm}$ carbonate buffer ( $\mathrm{pH} 9.5$ ) containing $50 \mathrm{~mm}$ sodium ascorbate. The supernatant was further brought to $35 \%$ saturation with solid ammonium sulfate. The resulting precipitate was collected by centrifugation and dialyzed against $50 \mathrm{~mm}$ phosphate buffer ( $\mathrm{pH} 6.0$ ) containing $50 \mathrm{~mm}$ sodium ascorbate. After dialysis, centrifugation was performed and the clear supernatant containing the crude phenoloxidase was isolated.

\section{Affinity column chromatography}

Crude phenoloxidase was partially purified by affinity column chromatography as previously described. ${ }^{10)}$ As shown in Fig. 1, the phenoloxidase activity was contained in the fraction (P-II fraction) eluted with $50 \mathrm{~mm}$ carbonate buffer $(\mathrm{pH} \mathrm{9.5)}$. The P-II fraction was dialyzed against $50 \mathrm{~mm}$ phosphate buffer $(\mathrm{pH}$ 6.0) and subsequently applied to a second affinity column, in exactly the same manner as described above (data not shown). The fraction collected was named P-II' for convenience. Furthermore, the P-II' fraction was subjected to a third affinity column chromatography, in the same manner, and the P-II" fraction was obtained (data not shown).

\section{Sephadex G-200 gel filtration}

The P-II" fraction was concentrated and applied to a Sephadex G-200 column. As shown in Fig. 2, the phenoloxidase activity was found in the G-II fraction. The G-II fraction was concentrated to be subjected to a second Sephadex G-200 column. The filtration pattern of protein and phenoloxidase activity were apparently both enantiographic (data not shown). The fraction collected was named G-II' for convenience. Purification steps are summarized in Table I.

\section{Polyacrylamide gel disc electrophoresis}

The homogeneity of the G-II' fraction was examined by polyacrylamide gel electrophoresis. The electrophoresis was performed in Tris-glycine buffer ( $\mathrm{pH} 8.3$ ), with a separation gel concentration of $6.0 \%$. As shown in Fig. 3, the G-II' fraction was electrophoretically homogeneous.

\section{Molecular weight determination}

The molecular weight of phenoloxidase determined by gel filtration with known standards using a Sephadex G-200 column was 330,000 (data not shown). 


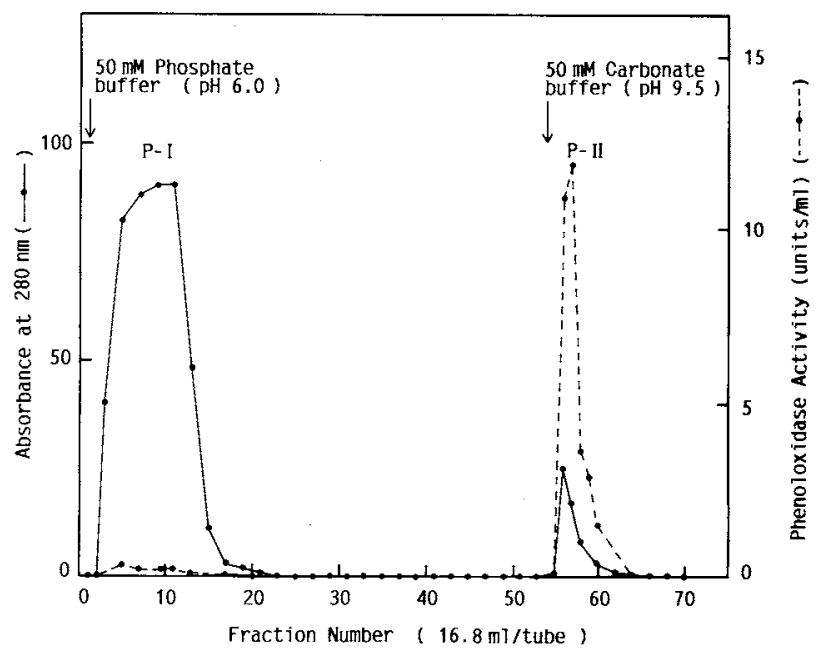

Fig. 1. Affinity Chromatography of Crude Phenoloxidase.

Crude phenoloxidase solution, prepared as described in the text, was applied to a $2.85 \times 7.8 \mathrm{~cm}$ column of Sepharose- $\mathrm{NH}-\left(\mathrm{CH}_{2}\right)_{2}-\mathrm{NH}-\mathrm{CO}-\mathrm{CH}_{2}-\mathrm{NH}-\mathrm{C}_{6} \mathrm{H}_{4}-\mathrm{COOH}$ which was equilibrated with $50 \mathrm{~mm}$ phosphate buffer, pH 6.0. Elution was performed with $50 \mathrm{~mm}$ carbonate buffer, $\mathrm{pH} 9.5$, with a flow rate of $30 \mathrm{ml} / \mathrm{hr}$. Solid lines (--) and dashed lines (----) indicate protein concentration $\left(A_{280}\right)$ and phenoloxidase activity, respectively. Aliquots of fractions were assayed for phenoloxidase activity as described in Materials and Methods.

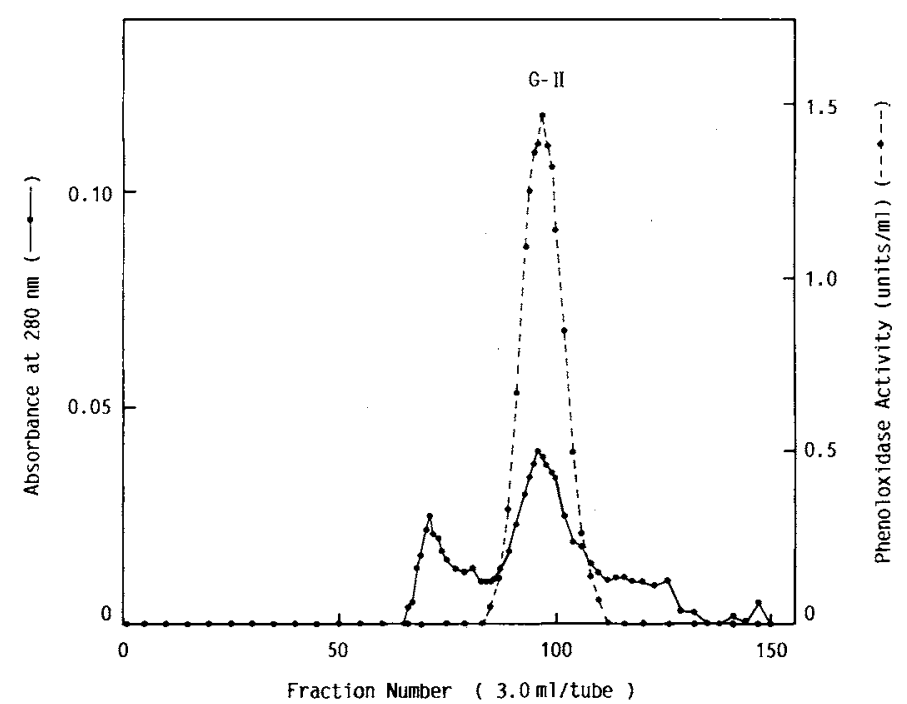

Fig. 2. Gel Filtration of P-II" Fraction through Sephadex G-200.

P-II" fraction from the affinity column was concentrated and applied to a $2.65 \times 110 \mathrm{~cm}$ column of Sephadex G-200. Elution was performed with $50 \mathrm{~mm}$ phosphate buffer, $\mathrm{pH} 6.0$, at a flow rate of $15 \mathrm{ml} / \mathrm{hr}$. Solid (-) and dashed (----) lines are protein concentration $\left(A_{280}\right)$ and phenoloxidase activity, respectively.

\section{Kinetic properties}

The kinetic properties of purified phenoloxidase (G-II fraction) were investigated using six catecholamines (DOPA, norepi- nephrine, epinephrine, dopamine, $N$-acetyldopamine, $N$ - $\beta$-alanyldopamine) as substrates. In all cases, the enzyme concentration used for the kinetic studies were within the range 
Table I. Summary of the Purification of Phenoloxidase from Housefly Pupae

The starting materials were $100 \mathrm{~g}$ of aged pupae. The assay conditions were as described in Materials and Methods. One unit of the enzyme activity was defined as the amount of enzyme which catalyzed the formation of $1 \mu$ mole of dopachrome per min, using $2 \mathrm{~mm}$ DOPA as substrate.

\begin{tabular}{|c|c|c|c|c|c|c|}
\hline Purification step & $\begin{array}{l}\text { Volume } \\
\text { (ml) }\end{array}$ & $\begin{array}{l}\text { Total } \\
\text { activity } \\
\text { (units) }\end{array}$ & $\begin{array}{l}\text { Total } \\
\text { protein } \\
(\mathrm{mg})\end{array}$ & $\begin{array}{c}\text { Specific } \\
\text { activity } \\
\text { (units/mg) }\end{array}$ & $\begin{array}{c}\text { Activity } \\
\text { yield } \\
(\%)\end{array}$ & $\begin{array}{l}\text { Purification } \\
\quad \text { (-fold) }\end{array}$ \\
\hline $\begin{array}{l}\text { Crude phenoloxidase } \\
\text { solution }\end{array}$ & 80 & 279 & 4650 & 0.06 & 100 & 1 \\
\hline $\begin{array}{l}\text { Affinity chromatography } \\
\text { (first) }\end{array}$ & 61 & 329 & 174 & 1.89 & 118 & 32 \\
\hline $\begin{array}{l}\text { Affinity chromatography } \\
\text { (second) }\end{array}$ & 100 & 182 & 55.6 & 3.27 & 65 & 55 \\
\hline $\begin{array}{l}\text { Affinity chromatography } \\
\text { (third) }\end{array}$ & 45 & 220 & 33.6 & 6.55 & 79 & 109 \\
\hline Sephadex G-200 (first) & 24 & 30.7 & 0.57 & 53.85 & 11 & 898 \\
\hline Sephadex G-200 (second) & 30 & 8.8 & 0.16 & 55.00 & 3 & 917 \\
\hline
\end{tabular}

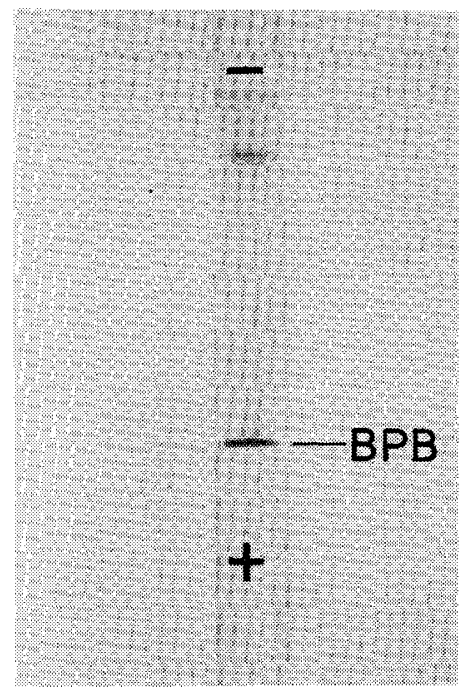

Fig. 3. Polyacrylamide Gel Disc Electrophoretic Pattern of Purified Phenoloxidase (G-II').

Acrylamide gels $(6.0 \%)$ were run with about $4.5 \mathrm{~cm}$ of separation gels using Tris-glycine buffer, $\mathrm{pH} 8.3$ at $2 \mathrm{~mA}$ per tube $(0.5 \times 6 \mathrm{~cm})$.

where a graph of initial velocity against enzyme concentration gave a straight line. With respect to the time course of the enzymecatalyzed oxidation, the points where the departure from linearity occurred differed considerably among the catecholamines. When DOPA (1.7 to $17.2 \mathrm{~mm}$, Fig. 4 ), epinephrine
( 0.32 to $3.16 \mathrm{~mm})$, and norepinephrine $(0.23$ to $2.28 \mathrm{~mm}$ ) were used as substrates for pupae phenoloxidase, the initial linear period of the forward reaction was at least 90 seconds in all cases. However, the observed initial linear period of the oxidative reaction was only 70 seconds for dopamine $(0.075$ to $0.6 \mathrm{~mm}), 25$ seconds for $N$ - $\beta$-alanyldopamine $(0.036$ to $0.36 \mathrm{~mm}$ ), and 20 seconds for $N$-acetyldopamine $(0.2$ to $1.97 \mathrm{~mm})$. The kinetic parameters such as Michaelis constants $(\mathrm{Km})$ and maximum velocity $\left(V_{\max }\right)$ were obtained through Lineweaver-Burk plots (Figs. 4, 5 and 6). A tendency for high concentrations of substrates to inhibit the oxidation of catecholamines by phenoloxidase was observed in all the substrates employed in this study. Figure 7 lists structures, $\mathrm{Km}$ and $V_{\max }$ for the oxidation of catecholamines by pupae phenoloxidase. The preferred order of substrates for pupae phenoloxidase in terms of affinity was $N-\beta$ alanyld opamine $>$ dopamine $>N$-acetyldopamine $>$ norepinephrine $>$ epinephrine $>$ DOPA, as estimated by the $K m$ values. The preferred order of enzymatic oxidation in terms of $V_{\max }$ was $N$-acetyldopamine $>N$ - $\beta$-alanyldopamine $>$ DOPA $>$ dopamine $>$ norepinephrine $>$ epinephrine. Negligible differences in molar extinction coefficients of oxidative products of these catecholamines were 


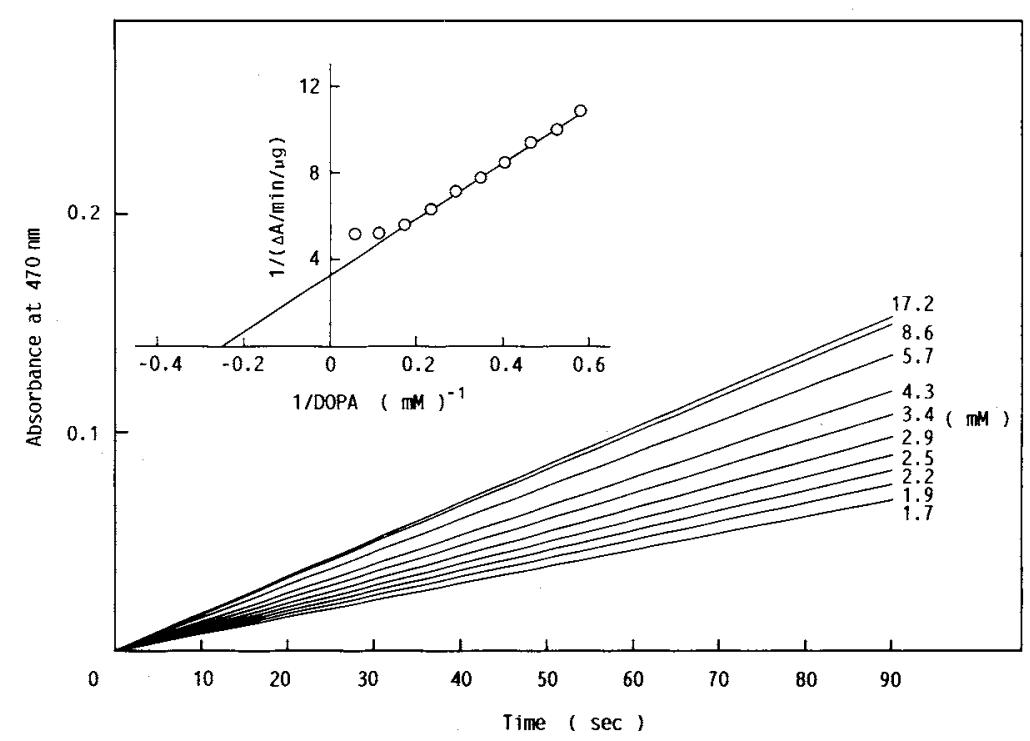

Fig. 4. Time Course and Lineweaver-Burk Plot of DOPA Oxidation by Pupal Phenoloxidase. The assay conditions were as described in Materials and Methods.

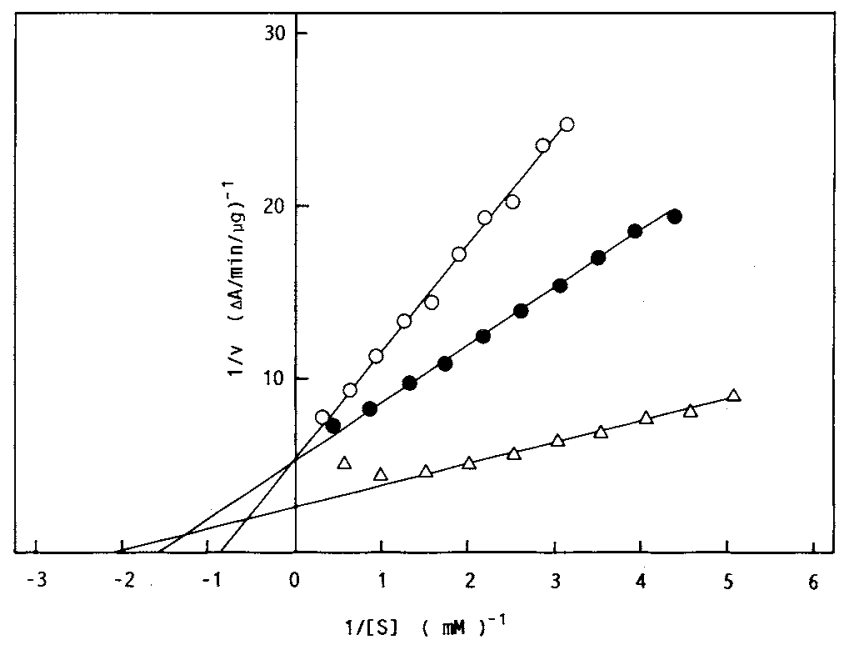

Fig. 5. Lineweaver-Burk Plots of Catecholamine Oxidation by Pupal Phenoloxidase.

$N$-Acetyldopamine $(\triangle)$, epinephrine $(O)$, and norepinephrine

assumed $^{7,11)}$ for comparison of $V_{\max }$.

\section{Discussion}

The purified phenoloxidase from pupae of the housefly was homogeneous on polyacrylamide gel disc electrophoresis and gel filtration by Sephadex G-200.

The affinity chromatography procedure was repeated until the P-I fraction was no longer observed. During the repeated affinity chromatographies, an elevation in total activity was observed. Possibly, this is due to removal of some inhibitory compounds which were bound to phenoloxidase or were included in the phenoloxidase fraction. We considered that the tightly bound compounds, which appear to affect the specific activity of purified phenol- 


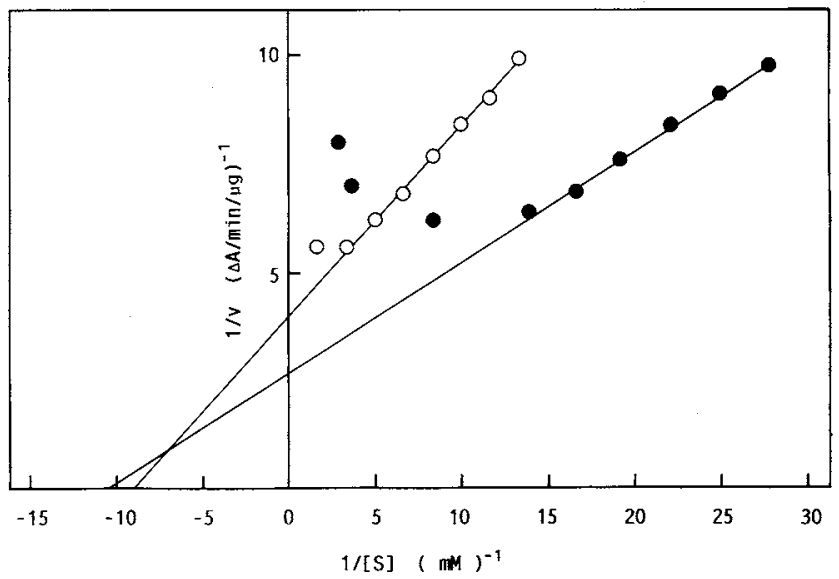

Fig. 6. Lineweaver-Burk Plots of Catecholamine Oxidation by Pupal Phenoloxidase. $N$ - $\beta$-Alanyldopamine (O) and dopamine (O).

\begin{tabular}{|c|c|c|}
\hline Compound & $\underset{(m M)}{K_{\text {m }}}$ & $\begin{array}{c}V_{\max } \\
(\Delta \mathrm{A} / \min / \mathrm{mg})\end{array}$ \\
\hline Dopa & & \\
\hline $\mathrm{HO}_{\mathrm{HO}}^{\mathrm{HO}}-\mathrm{CH}_{2}-\underset{\mathrm{NH}_{2}}{\mathrm{CH}} \mathrm{H}-\mathrm{COOH}$ & 3.93 & $\begin{array}{c}304 \\
(\triangle \mathrm{A} 470 \mathrm{~nm})\end{array}$ \\
\hline $\begin{array}{l}\text { Epinephrine } \\
\mathrm{HO}-\mathrm{OH} \\
\mathrm{HO}-\mathrm{O}-\mathrm{CH}-\mathrm{CH}_{2}-\mathrm{NH}_{-} \mathrm{CH}_{3}\end{array}$ & 1.13 & $\begin{array}{c}182 \\
\text { ( } \triangle \mathrm{A} 470 \text { nआ) }\end{array}$ \\
\hline $\begin{array}{l}\text { Norepinephrine } \\
\mathrm{HO}, \mathrm{OH} \\
\mathrm{HO}-\mathrm{CH}_{-} \mathrm{CH}_{2}-\mathrm{NH}_{2}\end{array}$ & 0.61 & $\begin{array}{c}186 \\
(\triangle \mathrm{A} 470 \mathrm{nIII})\end{array}$ \\
\hline 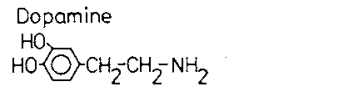 & 0.11 & $\begin{array}{c}250 \\
(\triangle \mathrm{A} 470 \mathrm{~nm})\end{array}$ \\
\hline $\begin{array}{l}\mathrm{N} \text {-acetyldopamine } \\
\mathrm{HO} \text { - } \mathrm{O}-\mathrm{CH}_{2}-\mathrm{CH}_{2}-\mathrm{NH}-\mathrm{COCH}_{3}\end{array}$ & 0.48 & $\begin{array}{c}383 \\
\text { ( } \triangle \mathrm{A} 390 \mathrm{~nm})\end{array}$ \\
\hline $\begin{array}{l}\mathrm{N} \text {-n-alanyldo pamine } \\
\mathrm{HO} \text { - } \mathrm{O}\rangle \mathrm{CH}_{2} \mathrm{CH}_{2}-\mathrm{NH}-\mathrm{CO}-\mathrm{CH}_{2}-\mathrm{CH}_{2}-\mathrm{NH}_{2}\end{array}$ & 0.10 & $\begin{array}{c}379 \\
(\triangle \mathrm{A} 390 \mathrm{~nm})\end{array}$ \\
\hline
\end{tabular}

Fig. 7. Structure and Kinetic Parameters for the Oxidation of Substrates by Pupal Phenoloxidase.

$K m$ and $V_{\max }$ were determined as described in the text. Values are the means from three experiments.

oxidase, to be basically removed by the third affinity chromatography.

The molecular weight of phenoloxidase was 330,000 by Sephadex G-200 gel filtration. Yamaura et ll $^{3)}$ reported that the molecular weight of phenoloxidase of larvae of the housefly was 340,000 . Further, the molecular weight of phenoloxidase obtained through the activation of purified latent phenoloxidase from the haemolymph of prepupae of the housefly, was the same as phenoloxidase isolated from larvae of the housefly. ${ }^{12)}$ Therefore, the molecular weights of larval and pupal phenoloxidase are very similar.

The substrate preference for pupal phenoloxidase appeared to agree fairly well with that of phenoloxidase purified from larvae of the houseffy. ${ }^{13)}$ The affinity of catecholamines for phenoloxidase decreased markedly by the presence of a carboxylic acid group on the side chain, as shown in the case of DOPA. Also, the addition of a hydroxyl group to the $\beta$ carbon of dopamine (see epinephrine and norepinephrine) led to a reduction of $\mathrm{Km}$ as well as $V_{\max }$. The high affinity obtained here in terms of low $K m$ values regarding $N-\beta$ alanyldopamine was intriguing since it has been identified as the major catecholamine metabolite involved in pupal tanning of Manduca sexta (L.) and several other species of insects. ${ }^{14)}$

Acknowledgments. Housefly pupae were generously provided from the laboratory of Pesticide Chemistry (Faculty of Agriculture, Kyushu University). The authors gratefully acknowledge the helpful instruction and continuous encouragement of Professor Akira Otakara (Faculty of Agriculture, Saga University) and Professor Susumu Hizukuri (Faculty of Agriculture, Kagoshima University). This work was supported in part by Grantsin-Aid for Scientific Research from the Ministry of 
Education, Science and Culture of Japan.

\section{References}

1) M. Funatsu and T. Inaba, Agric. Biol. Chem., 26, 535 (1962).

2) T. Inaba and M. Funatsu, Agric. Biol. Chem., 28, 206 (1964).

3) I. Yamaura, M. Yonekura, Y. Katsura, M. Ishiguro and M. Funatsu, Agric. Biol. Chem., 44, 55 (1980).

4) I. Yamaura, M. Yonekura, Y. Katsura, M. Ishiguro and M. Funatsu, Agric. Biol. Chem., 44, 2437 (1980).

5) K. J. Kramer, C. Nuntnarumit, Y. Aso, M. D. Hawley and T. L. Hopkins, Insect Biochem., 13, 475 (1983).

6) N. H. Horowitz and S. C. Shen, J. Biol. Chem., 197,
$513(1952)$.

7) H. S. Mason, J. Biol. Chem., 172, 83 (1948).

8) B. J. Davis, Ann. N. Y. Acad. Sci., 121, 406 (1964).

9) O. H. Lowry, N. J. Rosebrough, A. L. Farr and R. J. Randall, J. Biol. Chem., 193, 265 (1951).

10) T. Shimoda, M. Yonekura and M. Funatsu, Agric. Biol. Chem., 39, 2423 (1975).

11) H. W. Duckworth and J. E. Coleman, J. Biol. Chem., 245, 1613 (1970).

12) T. Tsukamoto, M. Ishiguro and M. Funatsu, Insect Biochem., 16, 573 (1986).

13) T. Tsukamoto, K. Maruta, T. Inaba, N. Yamasaki, Y. Aso, I. Yamaura and M. Funatsu, Biochem. International, 16, 785 (1988).

14) T. L. Hopkins, T. D. Morgan, Y. Aso and K. J. Kramer, Science, 217, 364 (1982). 